\title{
Laryngeal Lymphoepithelial Carcinoma
}

National Cancer Institute

\section{Source}

National Cancer Institute. Laryngeal Lymphoepithelial Carcinoma. NCI Thesaurus. Code C54341.

A rare and aggressive carcinoma that arises from the larynx. It is characterized by the presence of an undifferentiated carcinoma accompanied by a prominent reactive lymphoplasmacytic infiltrate. 